\title{
Derecho a la salud de personas detenidas o en prisión: la lección de una pandemia*
}

\author{
Marcela Verónica Chávez Hernández** \\ licmvchavez@gmail.com
}

\section{RESUMEN}

El 11 de marzo de 2020, la Organización Mundial de la Salud calificó como pandemia el brote de COVID-19 que asolaba al mundo; el contexto de alarma sanitaria mundial provocó, a nivel internacional, múltiples acciones como la instauración de un Fondo de Respuesta Solidaria contra la COVID-19 y el desarrollo del Ensayo clínico Solidaridad, que tiene por objeto buscar el tratamiento médico más adecuado para hacer frente al virus SARS-CoV-2. En el ámbito nacional, desde los gobiernos nacionales hasta los municipales, se tomaron medidas para contener los contagios y reducir los altos niveles de mortalidad generados por la pandemia. De manera prioritaria se emitieron recomendaciones e instrucciones para proteger a las personas identificadas como vulnerables tales como personas adultas mayores; personas con antecedentes o presencia de afecciones médicas; mujeres embarazadas; personas migrantes; y, personas viviendo en entornos cerrados, que agrupa a las personas privadas de su libertad, de manera preventiva o como parte de una sanción. El derecho a la salud es fundamental y, en el caso de las personas privadas de su libertad es preponderante conocer las obligaciones que genera a fin de que se establezcan los mecanismos necesarios para garantizarlo, considerando las experiencias resultantes de grandes eventos como una pandemia mundiales.

Palabras clave: derecho a la salud; derecho a la vida; responsabilidad estatal; pandemia; derecho internacional de los derechos humanos; libertad.

\footnotetext{
* Agradezco al Centro de Estudios Políticos y Constitucionales de Madrid, las facilidades otorgadas para la elaboración del presente artículo.

** Maestra en Derecho Procesal Constitucional por la División de Estudios de Posgrado de la UMSNH; Maestra en Derecho Procesal Acusatorio con Orientación a la Litigación Oral por la Universidad Nova Spania; Doctorante en Derecho por la Universidad de Guanajuato; Investigadora de estancia corta del Centro de Estudios Políticos y Constitucionales de Madrid.
} 


\title{
Right to health of people detained or in prison: the lesson of a pandemic
}

\begin{abstract}
On March 11, 2020, the World Health Organization classified the COVID-19 outbreak that devastated the world as a pandemic; The context of global health alarm led to, at the international level, multiple actions such as the establishment of a Solidarity Response Fund against COVID-19 and the development of the Solidarity clinical trial, which aims to seek the most appropriate medical treatment to face the SARS-CoV-2 virus. At the national level, from national to municipal governments, measures were taken to contain contagions and reduce the high levels of mortality generated by the pandemic. Recommendations and instructions were issued as a priority to protect people identified as vulnerable, such as the elderly; people with a history or presence of medical conditions; pregnant women; migrant people; and, people living in closed environments, which groups together people deprived of their liberty, preventively or as part of a sanction. The right to health is fundamental and, in the case of persons deprived of their liberty, it is preponderant to know their obligations in order to establish the necessary mechanisms to guarantee it, , considering the experiences resulting from major world events such as a pandemic.
\end{abstract}

Keywords: right to health; right to life; state responsibility; pandemic; International Law of human rights; Liberty.

Artículo recibido: 10 Agosto. 2021 Aceptado para publicación: 07. Setiembre. 2021 Correspondencia: licmvchavez@ gmail.com

Conflictos de Interés: Ninguna que declarar 


\section{ERARHUKUKATA}

Indéjurhía 11 marsu 2020 jimbo, indé Organización Mundial de la Salud arhikatauandaskusptieskak'erip'amenchakueskaindé COVID-19 jimbo, indéuenaspkak'amajkuniparhakpenianapuechani; xarhatasptiambemengajuánunijapkamaparhakpeni, kainstuxarhatasptimamaruambéúkuaengajindepkaindé Fondo de Respuesta Solidaria arhikatarhuueratinikaixiuniatarhukuniindé COVID-19 katamtuxangataniindéEnsayo clínico Solidaridad, engajatsikaanchekuarhikuajirinhanitsinajpekuaengauákaatarhukunikakenditaniindékerikuarhikua SARS-CoV-2. Iniireta México, iamindujuramutiecha, (estatal ka municipal) jankuarhitasptixijirinhani nena atarhukuniindep'amenchakuakerikuarhikuaka no xaniuánikuauarhinganiindép'amekuakuarhikuajimbo. Engasanderujingontkuepkapetasptikxiuandatsikukuechaengaarhimkak'uiripuechaniengakxi

no kanikuauinapekuajatsipka, t’arhepechakakutsimecha nena exetkujamani; istuk'uiripuechaengakxikankuarhijkamaterujaxiambep'amechakua; istukuxarheyurhit;; istuk'uiripunitamaticha; ka, imak'uiripuechaengakxionkuarjitinïrekuarhitinijaka, imak'uiripuechaengaksik'atakuarhitinijaka, engakxiionijakaia o istuengasosantkuonkuarhitinijaka. Indéjurhimikuatsinajpikuerikuajpekuajindestik'eriniatakua, ixijimboimak'uiripuecheriengakxik'atakuarhiotinijakajindestikanikuaukua, jimbouetarhixindisesimiteni nena jindeuaanchekuarhikuakauniimak’uiripuechakuajpianikaeskakauakaixiukuarhinieskanajakauaxakatinijuramukuarhu 


\section{INTRODUCCIÓN}

En las últimas décadas, una parte importante de los estudios generados en el ámbito jurídico han sido entorno a los derechos humanos. Su análisis en el contexto de desenvolvimiento del derecho penal ha llevado al replanteamiento de las figuras de Estado, víctima e imputado, así como a valorar la forma en que la autoridad debe responder a la conducta delictiva y las medidas que deben emplearse con la finalidad de lograr la reinserción de las personas responsables, sin perder de vista el respeto a su dignidad y garantizar sus derechos humanos. En México la adopción del garantismo, que se materializó en la justicia ordinaria a partir de la reforma constitucional de junio de 2008, exigió concentrar los esfuerzos en la consolidación de un sistema de tipo acusatorio que concluyera la vigencia, prácticas y deficiencias del modelo inquisitivo, desde la perspectiva de su enfoque antropocéntrico. Se creó, entonces, el marco jurídico necesario para privilegiar los derechos y garantías de las personas intervinientes en los procesos penales, siguiendo la línea que ha tomado cada vez mayor fuerza en el ámbito internacional.

En el caso de las personas responsables de la comisión de un hecho delictivo, la llamada reforma constitucional al sistema de justicia penal produjo, además, el replanteamiento de los objetivos del sistema penitenciario para desarraigar el concepto de readaptación y sus implicaciones. Esto ha tenido como efecto que, al momento de observar el artículo 18 constitucional, la atención sea acaparada por el hecho de que la reinserción y la prevención del delito se convierten en los objetivos fundamentales del sistema penitenciario, obviando la declaración de derechos que se realiza a favor de las personas en prisión.

Trabajo, capacitación, salud y deporte son tratados como los medios para lograr el fin de la reinserción, sin embargo, deben ser entendidos en un sentido más profundo como prerrogativas que el texto constitucional reconoce expresamente a las personas privadas de su libertad en centros penitenciarios, en armonía con los tratados e instrumentos internacionales de protección a los derechos humanos. Como todo derecho, los establecidos en el artículo 18 constitucional imponen una serie de obligaciones que los Estados deben cumplir al ser los responsables de la salvaguarda de estas personas, por el tiempo que duren bajo su tutela.

Desde entonces, y habiéndose reforzado los compromisos a través de la reforma constitucional en materia de derechos humanos de 2011, se han llevado a cabo diferentes acciones para mejorar la calidad de vida en los centros penitenciarios y garantizar el goce 
efectivo de los derechos de las personas que ahí habitan. Los Estados han asumido su papel de garante y los organismos de protección de derechos humanos se han posicionado como interventores del cumplimiento dado a las obligaciones, tanto nacionales como internacionales, en materia penitenciaria.

No obstante, la pandemia de SARS-CoV2 sufrida alrededor del mundo, ha vuelto a poner en evidencia la condición de vulnerabilidad en la que se encuentran las personas privadas de su libertad, en áreas de internamiento o centros penitenciarios. La imposibilidad de procurarse por sí mismas los medios para garantizar el ejercicio de sus derechos en el contexto de una enfermedad que ha cobrado millones de vidas, hace necesario recordar cuáles son las obligaciones de los Estados, particularmente con este sector de la población, y las implicaciones que conlleva el goce pleno de esta prerrogativa.

Valorar la realidad de un país como México, en materia de salud y sistema penitenciario, permiten dimensionar el tamaño del reto que se enfrenta y la importancia de garantizar de manera efectiva el disfrute de ese derecho. Es por ello que la primera parte de este trabajo se ha destinado a presentar algunas cifras del impacto provocado por el SARS-CoV2 en el país; exponer los índices poblacionales existentes en los centros penitenciarios; y, abordar la opinión de los organismos protectores de derechos humanos en torno al tema de la salud en personas en estos espacios de privación legal de la libertad.

La segunda parte, se centra en el análisis del derecho a la salud como derecho fundamental. Esta categoría, otorgada en 1946 por la Organización Mundial de la Salud, impulsó el surgimiento de un entramado jurídico especializado en esta materia, tendiente a la protección y garantía del derecho a la salud. Estos aspectos serán abordados en dicho apartado permitiendo conocer los principales instrumentos y autoridades en el tema, así como algunos criterios surgidos en torno a ello.

Entender el derecho a la salud implica reconocer que éste no se agota con los servicios médicos y que abarca los aspectos tanto físicos como mentales del individuo. Estas precisiones, así como un análisis más profundo sobre los alcances del derecho a la salud en los centros penitenciarios y áreas de internamiento, se realizan en la tercera parte de este trabajo donde, además, podrá conocerse el contenido de documentos como las Reglas Mínimas de las Naciones Unidas para el Tratamiento de los Reclusos y la postura que han asumido instancias como la Corte Interamericana de Derechos Humanos y la Comisión Nacional de los Derechos Humanos, sobre el goce efectivo de este derecho. 
La parte final se ha reservado para realizar algunas consideraciones sobre el derecho a la salud de las personas en detención o prisión. La pandemia por COVID-19 ha alentado la adopción de diversas medidas dirigidas a salvaguarda la salud de la población, especialmente de los que se encuentran en condición de vulnerabilidad como son las personas residentes en centros penitenciarios o áreas de internamiento. Estas medidas, originadas nacional e internacionalmente, parten del reconocimiento de la dignidad de la persona, de las limitaciones a su libertad y de las obligaciones del Estado como responsable de su custodia, cuestiones que serán analizadas en el cuarto apartado de este artículo.

Todas las reflexiones que aquí se presentan permiten tener un panorama general de la trascendencia de garantizar el derecho a la salud, a las personas detenidas o en prisión. La interdependencia que caracteriza los derechos humanos se hace evidente en el caso de esta prerrogativa que, en caso de verse vulnerada, puede tener graves consecuencias para las personas privadas de su libertad. Si bien, a partir del SARS-CoV2 se han tomado diversas acciones para asegurar el derecho a la salud en este sector, la lección más grande debe ser generar estrategias preventivas que permitan propiciar contextos seguros, con independencia de la existencia o no, de un motivo para ello.

\section{Centros Penitenciarios y salud: la realidad en México}

En diciembre de 2019, se detectó en la ciudad de Wuhan, China, una multiplicidad de casos de un padecimiento que posteriormente sería identificado como COVID-19. Esta enfermedad comenzó a esparcirse rápidamente, llegando casi a los ocho mil casos en China, para enero de 2020. Los índices de mortalidad del virus; la rapidez con la que se fue propagando, incluso más allá de las fronteras del país asiático; así como el desconcierto entre la comunidad médica sobre la atención más adecuada, dio como resultado que tres meses después de su aparición, la Organización Mundial de la Salud (OMS) calificara la situación como una pandemia.

En su discurso, el doctor Adhanom (2020), Director General de la OMS, reconoció que al menos hasta marzo de ese año, se habían identificado más de 118,000 casos en 114 diferentes países y causado la muerte de 4,291 personas, mientras que muchas otras se encontraban luchando en los hospitales por salir avante de dicha enfermedad, motivos por los cuales era posible calificar la propagación del virus como una pandemia. Reconocía que en los últimos años no se había hecho frente a una situación de este tipo en materia de salud, sin embargo, señalaba que se estaban llevando a cabo las acciones necesarias para combatirla. 
De manera enfática, hizo un llamado a todos los países a acatar las medidas impuestas para frenar la propagación del virus afirmando que:

Si los países se dedican a detectar, realizar pruebas, tratar, aislar y rastrear, y movilizan a su población en la respuesta, aquellos que tienen unos pocos casos pueden evitar que esos casos se conviertan en grupos de casos, y que esos grupos den paso a la transmisión comunitaria. Incluso en los países donde hay transmisión comunitaria o grandes grupos de casos, se puede dar la vuelta a la situación creada por este virus. (Adhanom Ghebreyesus, 2020, párr. 20 y 21)

Infortunadamente, los esfuerzos por detener el virus no rindieron los frutos esperados. Según cifras de la OMS (2020), hasta agosto de este año se lleva registro en América de 77,889, 496 casos acumulados de COVID-19, así como de 2, 019, 599 defunciones, constituyendo las muertes el 2,59\%. En cuanto a México, la misma organización reporta un total de 2,880,409 casos acumulados, con 241,936 muertes a causa de la pandemia, encontrándose por debajo de países como Colombia, Argentina, Brasil y Estados Unidos de Norteamérica, pero por encima de Perú, Chile, Canadá y Ecuador.

El Gobierno de la República Mexicana también ha transparentado sus estadísticas sobre el coronavirus; según datos compartidos por el Gobierno Federal (2021), hasta agosto de este año, México tiene un conteo de casos positivos estimados de 3, 100, 599, con 254,973 defunciones y 2, 270, 427 casos recuperados, siendo el género masculino en el que se presenta mayor índice de contagios. Los números muestran además que, actualmente, sólo el $17.13 \%$ de los casos son hospitalizados, mientras que el $82.87 \%$ se mantienen como ambulatorios.

Estas cifras permiten comprender por qué al día de hoy la pandemia de coronavirus se mantiene como un problema grave de salud general, que ha impulsado la implementación de distintas medidas tendientes a mitigar los contagios y, en la medida de lo posible, luchar por su erradicación. En México algunas de estas medidas han sido evitar las agrupaciones de personas en centros de trabajo y espacios públicos; la suspensión de actividades escolares en todos los niveles, así como de aquellas actividades no consideradas esenciales; generar campañas de información constantes sobre las medidas sanitarias; e, incentivar la aplicación de las vacunas que se han generado para ello. 
En todos los casos se ha buscado proteger de manera primordial a aquellos grupos considerados en condición de vulnerabilidad, entre los que se encuentran niñas, niños, mujeres embarazadas, personas adultas mayores, personas con enfermedades como hipertensión o diabetes, así como personas privadas legalmente de su libertad en algún centro de reinserción o área de internamiento quienes, particularmente, deben ser una de las prioridades del gobierno dada la responsabilidad que tiene de salvaguardar su vida e integridad, tal como lo ha señalado la Corte Interamericana de Derechos Humanos.

En este sentido, según datos del Instituto Nacional de Estadística y Geografía (2021), hasta la conclusión del 2020 se contabilizaron un total de 251 centros penitenciarios estatales, 15 federales y 53 especializados en adolescentes; se registró un ingreso a nivel nacional de 110,351 personas y un egreso de 93, 251, con lo que se estima que existe un aproximado de 211, 169 personas privadas de su libertad, entre adultos y adolescentes, en toda la República ( $\sin$ contar los 392 menores que acompañan a sus madres en los Centros). Dicha población se constituye mayormente de hombres, quienes alcanzan el 94.4\% del total, mientras el $5.6 \%$ se integra por mujeres.

Las cifras de personas privadas de la libertad en los centros penitenciarios, aunadas al número de personas que pasan temporalmente una detención en los espacios de internamiento de las instituciones de procuración de justicia, ${ }^{3}$ dan lugar a un importante índice poblacional que debe ser tomado en consideración a la hora de elaborar políticas públicas, especialmente las relacionadas a la salud, a fin de garantizar el goce efectivo de sus derechos. En el contexto actual de la pandemia, ello significa adoptar medidas eficaces para evitar contagios; garantizar el acceso a servicios de salud de calidad; y, gestionar las jornadas de vacunación correspondientes.

Sin embargo, el reto del gobierno mexicano en materia de salud es alto y se manifiesta en el índice de quejas presentadas ante los organismos protectores de Derechos Humanos. Hasta junio de 2021 se habían presentado ante la Comisión Nacional de los Derechos Humanos un aproximado de 1,981 quejas contra el sector salud; de ellas, 512 correspondieron al sistema

\footnotetext{
${ }^{3}$ Dentro de los resultados presentados por el INEGI, tanto por lo que ve al Censo Nacional de Sistema Penitenciario Federal y Estatales 2021, como al Censo Nacional de Procuración de Justicia Estatal 2020, se advierte la ausencia de información sobre el total de personas ingresadas a las áreas de internamiento o "separos". Por su parte, el Registro Nacional de Detenciones tampoco ofrece información estadística al respecto fungiendo únicamente, de momento, como una plataforma de consulta que permite conocer si una persona se encuentra detenida, ante qué autoridad está puesta a disposición y otros datos importantes para garantizar la seguridad jurídica.
} 
penitenciario y centros de internamiento; de la cuales, a su vez, 302 fueron por omitir proporcionar atención médica, 9 por omitir suministrar medicamentos y 1 por omitir información sobre el estado de salud. (Comisión Nacional de los Derechos Humanos [CNDH], 2021)

Pese a los avances que se han alcanzado, el análisis realizado a los centros penitenciarios por el organismo nacional de protección a derechos humanos en 2020, da muestra de las carencias que todavía existen en dichos espacios en relación con los servicios de salud. A raíz de los resultados obtenidos en el Diagnóstico Nacional de Supervisión Penitenciaria, la CNDH (2020) reconoció que "se continúan arrastrando ciertas deficiencias, tales como, insuficiencias en los servicios médicos, de recursos materiales, de infraestructura, de servicios de salud, y humana, entre otras" (p. 7). Esta situación impide un ejercicio efectivo de los derechos, que pone en riesgo la salud y calidad de vida de las personas recluidas.

En el diagnóstico, Estados como Baja California, Chihuahua, Ciudad de México, Estado de México, Guanajuato, Jalisco, Nuevo León y Querétaro, fueron evaluados positivamente en materia de salud, al constatarse por parte de la CNDH una buena calidad en la atención médica otorgada; no obstante, del total de centros estatales visitados, el $38.9 \%$ presentaron deficiencias importantes, mientras que el porcentaje en los federales fue de $87.5 \%$ (CNDH, 2020, pp.287 y ss.). Estas irregularidades son una manifestación de la violencia y carencias que sufren las personas al interior de los centros penitenciarios.

Las condiciones de vulnerabilidad que derivan de estas insuficiencias, han motivado que las personas en reclusión busquen el amparo de los organismos no jurisdiccionales de derechos humanos. En este sentido, según los datos derivados del diagnóstico, los organismos de protección recibieron en 2020 un total de 5,502 quejas, es decir, 800 inconformidades más que en 2019, de las cuales 1,304 fueron por violaciones al derecho a la salud. Los Estados con mayor incidencia fueron Michoacán, con 2,349 quejas; Estado de México, con 1,135 quejas; y, Baja California, con 673 quejas. (CNDH, 2020, pp.465 y ss.).

Estas estadísticas evidencian la realidad de México en materia de salud al interior de los Centros penitenciarios, la cual vino a recrudecerse con motivo de la pandemia de SARSCoV2. Si bien es cierto que, en el caso de la crisis sanitaria, la CNDH (2020) reportó que se habían tomado diversas medidas para contener los contagios y salvaguardar la salud de las personas recluidas, también lo es que las actividades de supervisión reportan irregularidades 
que comprometen el derecho a la salud, la integridad física y la vida incluso, desde antes de la aparición del virus.

\section{La salud como derecho fundamental}

En 1946, cuatro años después del surgimiento de la Organización de las Naciones Unidas, se suscribió en el marco de la Conferencia Sanitaria Internacional realizada en Nueva York, un documento a través del cual se consagraba a la salud como un derecho fundamental, al que deben tener acceso todos los seres humanos. ${ }^{4}$ En la llamada Constitución de la Organización Mundial de la Salud (1946), quedó plasmado el reconocimiento de que el derecho fundamental a la salud no era únicamente la ausencia de padecimientos, sino "una condición fundamental para lograr la paz y la seguridad" (párr. 4), que necesitaba de la voluntad de individuos y autoridades.

A la luz de este objetivo, en el documento se estableció como finalidad de la Organización Mundial de la Salud, "alcanzar para todos los pueblos el grado más alto posible de salud" (Constitución de la Organización Mundial de la Salud, 1946, p. 8), legitimándola para actuar como autoridad directiva y coordinadora en asuntos de sanidad internacional; ayudar a los gobiernos, a su solicitud, a fortalecer sus servicios de salubridad; promover y realizar investigaciones en el campo de la salud; suministrar información, consejo y ayuda en el mismo campo; entre otras.

Los Estados parte aceptaron sujetarse a la OMS como máxima autoridad en materia de salud y cumplir con un mínimo de obligaciones que contenía dicho instrumento, entre las que se encuentran, la rendición anual de un informe relativo a las medidas implementadas para alcanzar el máximo de salud de sus habitantes, así como la entrega de los informes estadísticos y epidemiológicos que les fuesen solicitados. (Constitución de la Organización Mundial de la Salud, 1946). A partir de entonces los esfuerzos por mejorar las condiciones de salud en el mundo fueron consolidándose y evolucionando.

A la Constitución de la OMS siguieron, en el ámbito internacional, la Declaración Universal de Derechos Humanos (1948) que reconoce como derecho de toda persona, "un nivel de vida adecuado que le asegure, así como a su familia, la salud y el bienestar, y en especial la alimentación, el vestido, la vivienda, la asistencia médica y los servicios sociales necesarios" (art. 25), así como el Pacto Internacional de Derechos Económicos, Sociales y Culturales,

\footnotetext{
${ }^{4}$ Dicho documento fue suscrito por México ese mismo año, entrando en vigor dos años después mediante su publicación en el Diario Oficial de la Federación.
} 
adoptado en 1966, que recogió a través de su numeral 12 el derecho a la salud como una prerrogativa prioritaria e integral de todas las naciones.

La conformación de un marco jurídico universal en materia de salud, permitió superar aquellos esquemas que conducían a entender que existían derechos con mayor importancia que otros. Como señala De la Torre Torres (2006), "las profundas divisiones ideológicas en el mundo durante los años cincuenta condujeron a categorizaciones de los derechos humanos que ignoraban la perspectiva holística propugnada por la Declaración Universal” (p. 307). Sin embargo, el posicionamiento adoptado en cuestión de salud, afianzó el camino para retomar en enfoque integral y lograr nuevamente la homologación.

Bajo esta perspectiva, los derechos económicos, sociales, culturales y ambientales, no pueden ser concebidos como derechos secundarios a los derechos civiles y políticos, ni subsidiarios de estos, como tampoco su existencia presupone una prelación frente a los derechos que Vasak identificó como de tercera generación. Todos los derechos forman parte de un plan sistémico que tiene como fin la protección y desarrollo integral del individuo, en todas sus esferas, por lo que los Estados deberán superar cualquier visión generacional que impida su materialización.

En el caso de México, el derecho a la salud fue considerado dentro del artículo $4^{\circ}$ constitucional. Pese a la brevedad del enunciado constitucional, la Primera Sala de la Suprema Corte de Justicia de la Nación (2019) ha señalado que esta prerrogativa debe ser interpretada en dos dimensiones: una individual y una social. Por lo que ve a su carácter individual, declaró que "el derecho a la salud se traduce en la obtención de un determinado bienestar general integrado por el estado físico, mental, emocional y social de la persona, del que deriva otro derecho fundamental, consistente en el derecho a la integridad físicopsicológica" (p. 486).

La primera vertiente exhibe la complejidad del derecho a la salud y evoca el contenido de la normativa internacional, que lo proyecta como un elemento fundamental para un nivel de vida adecuado, tal como lo indicó el Pacto Internacional de Derechos Económicos, Sociales y Culturales (1966). Desde este enfoque, mente y cuerpo son el objeto dual del derecho a la salud, por lo que sólo las políticas públicas que atiendan este carácter psico-físico del individuo podrán considerarse efectivas, para el goce de dicha prerrogativa. Se reitera, el derecho a la salud no se agota con la atención médica de los padecimientos físicos. 
La segunda dimensión, es decir, la referente a lo social o público, la atribuye a la obligación del Estado "de atender los problemas de salud que afectan a la sociedad en general, así como en establecer los mecanismos necesarios para que todas las personas tengan acceso a los servicios de salud" (SCJN, 2019, p. 486). Esto incluye la generación de políticas públicas efectivas, estudios y diagnósticos generales de salud, así como la prevención de situaciones de riesgo que puedan comprometer o menguar la calidad de vida de las personas. Es en este aspecto en el que se ubica la obligación de los Estados a atender con oportunidad los efectos de una crisis de salud, como la pandemia.

Cabe aclarar que el derecho a la salud no es una prerrogativa autónoma, es decir, no corresponde únicamente al individuo asegurarse su propio bienestar físico y mental, como tampoco es obligación exclusiva del Estado responsabilizarse de forma absoluta por la salud de todos y cada uno de los gobernados. Se trata de una responsabilidad compartida, en la que convergen ambos actores para asegurar un nivel de vida adecuado, tanto en lo individual como en lo social.

No obstante, en el caso de las personas en condición de vulnerabilidad el Estado puede subrogar esta responsabilidad a efecto de cubrir las carencias de tipo personal que impiden el goce del derecho. Incluso, el Estado puede apoyarse del sector privado para garantizar los servicios necesarios, sin que ello sea una eximente de sus responsabilidades. La Primera Sala de la Suprema Corte de Justicia de la Nación abundó sobre este supuesto al decir que las obligaciones resultantes del derecho a la salud, son exigibles aún en tratándose de particulares que presten servicios de este tipo.

En tesis aislada de rubro EL DERECHO FUNDAMENTAL A LA SALUD. IMPONE DEBERES TANTO A LOS PODERES PÚBLICOS COMO A LOS PARTICULARES QUE SE DEDICAN AL ÁMBITO DE LA SALUD, la Primera Sala señaló (2013) que "del análisis del contenido y estructura del derecho fundamental a la salud, se desprende que éste es vinculante no sólo frente a los órganos del Estado, sino que adicionalmente, posee eficacia jurídica en ciertas relaciones entre particulares" (p. 626). Este argumento modifica la idea del derecho a la salud como responsabilidad bipartita pues, en el caso de los servicios médicos particulares, debe incluirse a los integrantes del sector privado.

Una segunda precisión que cabe realizar es que el derecho a la salud no opera de la forma en que lo haría el principio de definitividad en el Juicio de Amparo, es decir, el derecho a la salud no exige que el gobernado agote los servicios de salud particulares para poder acceder 
a los servicios de salud estatales. En su carácter de derecho, el legislador brindó al ciudadano la libertad de decidir hacer uso de los servicios de salud públicos o particulares, sin que la elección de estos últimos tenga efectos preclusivos en el derecho de acudir a cualquier instancia del sector público para recibir la atención médica necesaria.

La incorporación del derecho a la salud al texto constitucional exigió la emisión de una ley secundaria en la materia. En consecuencia, el 7 de febrero de 1984 se publicó en el Diario Oficial de la Federación la Ley General de Salud, reglamentaria del artículo $4^{\circ}$ constitucional. El constituyente actuó con minuciosidad en la construcción de este cuerpo normativo ya que, el concepto de salud que hasta el momento se había utilizado en el ámbito internacional, fue detallado para precisar sus implicaciones:

\section{“Artículo 2o.- El derecho a la protección de la salud, tiene las siguientes finalidades:}

I. El bienestar físico y mental de la persona, para contribuir al ejercicio de sus capacidades;

II. La prolongación y mejoramiento de la calidad de la vida humana;

III. La protección y el acrecentamiento de los valores que coadyuven a la creación, conservación y disfrute de condiciones de salud que contribuyan al desarrollo social;

IV. La extensión de actitudes solidarias y responsables de la población en la preservación, conservación, mejoramiento y restauración de la salud;

V. El disfrute de servicios de salud y de asistencia social que satisfagan eficaz y oportunamente las necesidades de la población. Tratándose de personas que carezcan de seguridad social, la prestación gratuita de servicios de salud, medicamentos y demás insumos asociados;

VI. El conocimiento para el adecuado aprovechamiento y utilización de los servicios de salud;

VII. El desarrollo de la enseñanza y la investigación científica y tecnológica para la salud, $\mathrm{y}$

VIII. La promoción de la salud y la prevención de las enfermedades." (Ley General de Salud, 2021, art. 2).

La proyección que se realiza de la salud desde el enfoque de la Ley General, procura asegurar el aspecto de una protección integral. No se actualiza a partir de la existencia de un padecimiento, ni se restringe al otorgamiento de atenciones médicas u hospitalarias, como reiteradamente se ha señalado a lo largo de este trabajo. El derecho a la salud que se fragua 
a través de la ley general explaya minuciosamente la declaración efectuada en el cuerpo constitucional, contemplando de manera expresa otros aspectos como la educación, la concienciación y la atención, tanto física como mental del individuo.

Las reflexiones realizadas hasta este momento con relación al derecho a la salud, ponen de manifiesto la amplitud y complejidad de esta prerrogativa con relación a los diferentes aspectos que las autoridades deben observar para alcanzar su efectiva garantía. En una declaración realizada dos años antes de la crisis sanitaria por COVID-19, el doctor Adhanom (2017) sostuvo que uno de los aspectos prioritarios de la organización era alcanzar la cobertura sanitaria universal. En sus palabras se percibía la esencia de la salud como un derecho social pues afirmaba que:

“(...) que todo el mundo debe tener acceso a los servicios de salud que necesita, cuando y donde los necesite, sin tener que hacer frente a dificultades financieras" (Adhanom Ghebreyesus, 2017, párr. 4).

Por consiguiente el Estado se encuentra obligado a llevar todas las acciones que sean necesarias, para garantizar que todas y cada una de las personas integrantes de la sociedad tengan acceso al ejercicio de este derecho, especialmente a aquellos grupos que se encuentran en condición de vulnerabilidad, eliminando cualquier barrera que pueda impedirle el acceso a una salud polivalente. Para la Primera Sala de la Suprema Corte de Justicia de la Nación (2017) el derecho a la salud pleno asigna tres principales obligaciones a los Estados.

La primera de ellas atiende a la protección del núcleo fundamental de estos derechos, mediante la adopción de acciones inmediatas que protejan la dignidad humana, es decir, que garanticen el reconocimiento de la persona como sujeto de derechos; la segunda, su realización progresiva, a través de la generación de políticas públicas constantes que permitan el cumplimiento certero de los objetivos, lo que implica el establecimiento de metas a corto, mediano y largo plazo para asegurar su progresividad; y, la tercera, referente a la no adopción de medidas regresivas, que impida una disminución en la satisfacción ya alcanzada previamente.

Todo lo anterior ha conducido al reconocimiento del derecho a la salud no sólo como una prerrogativa de tipo prestacional, sino como un requisito sine qua non para el respeto de la dignidad humana. Recordemos que desde una perspectiva generacional los DESCA surgen 
para generar condiciones de igualdad en la calidad de vida de las personas esto significa, como señala Camacho Solís (2014):

“(...) el hacer y el vivir desde la propia acción y elección sin infringir las ventanas sociales, disfrutando los derechos básicos como mínimos indispensables para vivir una vida en la que se respete la dignidad humana, se cuente con oportunidades reales de salud e integridad física, mantenimiento de relaciones afectivas, educación, control sobre el entorno, esto es, tener capacidades (oportunidades) para funcionar de manera integral y armónica como persona, y como parte de un hogar mayor llamado tierra, en donde los vínculos de justicia sean evidentes para todos los seres sensibles." (p. 43)

El andamiaje conceptual y reflexivo sobre la salud le ha valido la categoría de derecho fundamental, así como elemento básico para garantizar la dignidad de la persona. Su garantía influye en un adecuado despliegue de la personalidad y el ejercicio de otros derechos como la vida, la alimentación y la educación. Por tanto, el Estado debe reconocer y asumir su carácter de garante a efecto de asegurar su ejercicio y protección, con independencia de las situaciones de ventaja o desventaja que existan en un momento o lugar determinado.

\section{Implicaciones del derecho a la salud en Centros penitenciarios o áreas de internamiento}

Ya se ha señalado que el derecho a la salud debe ser entendido como "el estado de completo bienestar físico, mental y social, y no solamente la ausencia de afecciones o enfermedades" (Constitución de la Organización Mundial de la Salud, 1946, párr. 2), cuya responsabilidad resulta compartida entre el Estado y los particulares. Sin embargo, en el caso de las personas privadas de su libertad esta obligación recae principalmente en el aparato gubernamental, quien se convierte en el principal responsable de proveer las condiciones de vida necesarias para la protección de este derecho.

En diversas ocasiones, la Comisión Interamericana de Derechos Humanos (CIDH) ha analizado la situación en la que se encuentran las personas privadas de su libertad; por ejemplo, en el Informe de la Comisión Interamericana de Derechos Humanos sobre la situación de las personas privadas de libertad en Honduras reconoció, entre otros aspectos, un mayor grado de vulnerabilidad de este sector de la sociedad y la existencia de diversas carencias o deficiencias en los sistemas penitenciarios, que de manera conjunta constituyen violaciones sistemáticas a los derechos humanos. (CIDH, 2013) 
Afirmó la Comisión Interamericana (2013) que un control adecuado de los Centros de internamiento podría derivar en la mejor protección de los derechos humanos de las personas que residen en ellos. Esto implica que el Estado asuma sus obligaciones y administre de manera adecuada las necesidades penitenciarias, con el fin de garantizar la seguridad de las personas internas. Con anterioridad, en un informe similar la CIDH había aclarado (2011) que las obligaciones de las autoridades no se limitan a la vigilancia y custodia de los reclusos ya que, en el caso de la salud, debe incluir la provisión de servicios y espacios adecuados para garantizar su vida e integridad personal.

Sobre el mismo tema, por su parte, la Corte Interamericana de Derechos Humanos (2006) señaló que la protección de la integridad personal de las personas reclusas, supone la obligación de adoptar las necesarias para mantener un "estándar adecuado de salud -que de no existir- debe ser calificada de tratamiento inhumano" (p. 93). Esta identificación de la falta de un nivel adecuado de salud con los tratos inhumanos, considerados como tal de acuerdo con la Convención contra la tortura y otros tratos o penas crueles, inhumanos o degradantes (1984), es transcendental para refrendar el valor sempiterno de la dignidad humana inherente al modelo garantista.

A partir de ello, el Tribunal Internacional ha declarado la responsabilidad internacional de varios Estados, en casos donde la salud de personas privadas de su libertad en centros penitenciarios o áreas de internamiento se ha visto menguada o no debidamente garantizada por omisiones atribuibles a las autoridades. Ejemplo de esto es el caso Juan Humberto Sánchez vs Honduras donde se reiteró la responsabilidad del Estado de salvaguardar la vida de las personas a su disposición o tutela (Corte IDH, 2003); así como el caso Díaz Peña vs Venezuela donde, además, la falta de condiciones de vida digna se identificaron como una violación a la Convención Americana de Derechos Humanos (Corte IDH, 2012).

Resulta importante conocer el contenido de las también conocidas como Reglas Mínimas de las Naciones Unidas para el Tratamiento de los Reclusos (1955) que, al respecto, señalan que las autoridades están obligadas a proveer a las personas internas, agua, artículos de aseo, ropa y alimentación, indispensables y necesarios, para asegurarles su salud e higiene. Declara que la prestación de servicios médicos gratuitos corresponde al Estado el cual, además, está obligado a contar con un servicio de atención sanitaria que promueva, evalúe y fomente la adecuada salud física y mental de las personas en espacios de internamiento. 
Estos derechos inherentes a la salud de las personas en prisión o detención, comprenden desde su llegada hasta el seguimiento que se otorgue de manera posterior a su egreso, vinculándose de manera estrecha con otras prerrogativas como no ser sujeto de tortura o tratos crueles inhumanos o degradantes y el respeto a la dignidad, como se ha señalado anteriormente, pues instruye que desde su ingreso, las personas puedan ser valoradas para descartar la presencia de huellas de violencia, así como la identificación de afecciones que requieran atención médica. En términos del numeral 30 de las Reglas (1955):

"Un médico u otro personal de la salud competente, esté o no a las órdenes del médico, deberá ver a cada recluso, hablar con él y examinarlo tan pronto como sea posible tras su ingreso y, posteriormente, tan a menudo como sea necesario. Se procurará, en especial:

a. Reconocer las necesidades de atención de la salud y adoptar todas las medidas necesarias para el tratamiento;

b. Detectar los malos tratos que los reclusos recién llegados puedan haber sufrido antes de su ingreso;

c. Detectar todo indicio de estrés psicológico o de otra índole causado por la reclusión, incluidos el riesgo de suicidio o autolesión y el síndrome de abstinencia resultante del uso de drogas, medicamente o alcohol, y aplicar todas las medidas o tratamientos individualizados que corresponda;

d. Facilitar a los reclusos de quienes se sospeche que sufren enfermedades contagiosas aislamiento médico y un tratamiento apropiado durante el periodo de infección;

e. Determinar la capacidad física de cada recluso para trabajar, hacer ejercicio y participar en otras actividades, según corresponda.” (art. 30)

Es importante indicar que, desde el punto de vista internacional, un efectivo derecho a la salud comprende también la adecuada capacitación e independencia de los servicios médicos, ya que estos necesitan del margen necesario para verificar de manera imparcial y autónoma el estado de salud de una persona detenida o en prisión. Es a través de la implementación de estas medidas que los Estados podrán asegurarse de cumplir con la aspiración de un estándar adecuado de salud, aún en el caso de aquellas personas que no 
pueden ejercer con autosuficiencia sus derechos, con motivo de una restricción temporal legal de su libertad.

De esta forma, el derecho a la salud aumenta sus exigencias en tratándose de personas privadas de su libertad en centros penitenciarios o áreas de internamiento, toda vez que como lo ha sostenido la Corte Interamericana de Derechos Humanos (2020), “el Estado, como responsable de los establecimientos de detención, es el garante de estos derechos de los detenidos" (p. 5). En consecuencia, las acciones de los gobiernos no deben limitarse a prevenir o erradicar cualquier acto que dificulte el acceso al interior de los espacios de internamiento de los servicios e instituciones del sector salud sino, además, garantizar que en el interior de éstos se satisfagan las necesidades alimentarias, médicas, psicológicas y de higiene inherentes a garantizar la seguridad y trato digno de las personas.

\section{Consideraciones finales sobre el derecho a la salud de personas detenidas o en prisión}

La pandemia por COVID-19 que actualmente sufre el mundo entero ha llevado a los diferentes gobiernos a adoptar diversas medidas tendientes a salvaguardar el derecho a la salud de millones de personas. La mayoría de ellas se enfocan en mantener una difusión e información constante sobre el virus SARS-COV-2, sus efectos, las formas en las que se pueden evitar los contagios y en fechas recientes campañas de vacunación contra el virus. En el caso de algunos sectores de la sociedad estas medidas han incluido un cuidado especial por el grado de vulnerabilidad en el que se encuentran, siendo ejemplo de ello las personas en detención o privadas legalmente de su libertad.

Para el caso de éstas, la OMS, en conjunto con la Oficina de las Naciones Unidas contra la Droga y el Delito y el Alto Comisionado de las Naciones Unidas para los Derechos Humanos emitieron un comunicado en el cual hacían énfasis en la necesidad y urgencia de reducir la aparición de esa enfermedad en los espacios carcelarios, así como vigilar la observancia de las medidas preventivas necesarias para evitar la aparición de casos de contagio al interior de dichos espacios, instando a fortalecer la coordinación entre las autoridades encargadas de la justicia y la sanidad a efecto de velar por el respeto a los derechos de estas personas, (OMS, UNODC, ACNUDH, 2020).

\section{Para la triada de autoridades internacionales fue importante señalar que:}

"Habida cuenta del hacinamiento que se produce en muchos centros de detención, algo que pone en peligro la higiene, la salud, la seguridad y la dignidad humana, queda claro que no basta con aplicar una respuesta 
sanitaria para la COVID-19 en esos entornos. El hacinamiento supone un obstáculo infranqueable a la prevención, preparación y respuesta ante esta enfermedad." (OMS et al., 2020, párr. 3).

Por tal motivo se realizó un exhorto a las autoridades, con el fin de limitar los casos de prisión preventiva, reducir el hacinamiento en los lugares de internamiento y privilegiar el uso de otras medidas alternativas que incluyeran una mayor consideración en caso de personas adultas mayores y personas con enfermedades previas, que pudieran verse afectadas más fácilmente por el coronavirus, a las cuales pudiera incluso dejarse en libertad. Alertando de la necesidad de tomar acciones inmediatas y firmes, solicitaron la implementación de medidas de higiene y limpieza en esos espacios, a fin de evitar el surgimiento de casos de contagio.

Reconocían que, si bien la obligación de garantizar la seguridad y salud de las personas detenidas o privadas de su libertad era una constante para los Estados, la existencia de una pandemia mundial obligaba a potencializar los servicios de salud, evitando la realización de conductas que pudieran resultar discriminatorias en contra de las personas en custodia del Estado, en centros de internamiento penitenciario. Añadían que, "las poblaciones de reclusos tienen una mayor proporción de personas con trastornos provocados por el uso de ciertas sustancias, infecciones por el VIH, tuberculosis y hepatitis B y C, en comparación con la población general" (OMS et al., 2020, párr. 9).

En virtud de ello, se requirió la coordinación entre todas las autoridades se reforzara a fin de evitar que la pandemia afectara el suministro de medicamentos a las personas reclusas en tratamiento, lo que suponía establecer un sistema de salud que, pese a las complicaciones propias de la crisis mundial sanitaria, pudiese brindar atención ininterrumpidamente, sobre todo en el caso de padecimientos considerados graves como $\mathrm{VIH}$, diabetes o tuberculosis. Para estas instancias internacionales es menester que los Estados tengan conciencia sobre la dimensión de esta crisis y de la importancia de cumplir con sus obligaciones, pues esto asegurará el respeto a los derechos humanos (OMS et al., 2020).

Finalmente, instaban a los líderes políticos a no perder de vista el respeto de los derechos humanos durante el periodo de pandemia, reiterando la obligación de conducirse de conformidad con los lineamientos internacionales contenidos en documentos como las Reglas Mínimas para el Tratamiento de los Reclusos de las Naciones Unidas, debiendo apostar por reducir, y en la mayor medida posible evitar, los contagios en los centros de 
internamiento, brindando las condiciones de salud necesarias para tal efecto y, en su caso, acatando las recomendaciones, instrucciones y observaciones de las autoridades sanitarias. Pronunciamientos como el anterior son de sumo interés a la luz de la justicia y los derechos humanos. Si bien, de manera previa al surgimiento del COVID-19 autoridades internacionales como la Corte IDH (2004), habían exhortado la utilización de la prisión preventiva como una medida excepcional, la crisis sanitaria mundial derivada del coronavirus ha conducido a que las autoridades realicen ejercicios de valoración de los casos para determinar cuáles de ellos realmente son acreedores de una privación de la libertad. A su vez, estos ejercicios de ponderación exigen una mayor capacitación y sensibilización por parte de los operadores jurídicos como Ministerios Públicos, Defensores y Jueces, a fin de lograr la despresurización de las prisiones.

No obstante, cabe preguntarse si la ponderación de los casos con motivo de una pandemia como la suscitada actualmente, podría poner en riesgo el acceso a la justicia de las víctimas u ofendidos o, en su caso, si este tipo de decisiones podría tener efectos secundarios sobre el sistema de justicia y la impunidad, pues se trata de un escenario nuevo en el que se ha hecho más uso de la razón que de la experiencia, en comparación con otros sucesos. Con independencia de ello, no cabe duda que los Estados deben asumir una responsabilidad mayor respecto de las personas detenidas o en prisión pues de ellos depende que su derecho a la salud sea efectivamente respetado.

En el caso de México, también se han tomado medidas encaminadas a fomentar el respeto del derecho a la salud de las personas detenidas, de frente al coronavirus. Muestra de lo anterior se encuentra en el documento emitido por la Comisión Nacional de los Derechos Humanos, en abril de 2020, bajo el título de "Pronunciamiento para la adopción de medidas emergentes complementarias en favor de las personas privadas de la libertad en la República Mexicana, frente a la pandemia por COVID-19", que constituye una acción contundente para hacer frente de manera oportuna y efectiva a los retos que presentaba la crisis mundial de salud, particularmente hacia grupos en condición de vulnerabilidad como las personas privadas de la libertad.

En dicho documento se reconocía la obligación del Estado de actuar como garante de los derechos humanos de las personas en detención o privadas de su libertad. (CNDH, 2020) En alegoría a los argumentos vertidos por la Corte Interamericana de Derechos Humanos, el organismo protector federal de derechos humanos señalaba que "el Estado tiene la 
obligación erga omnes de proteger a todas las personas que se encuentren bajo su jurisdicción, no solo en relación con su propio poder, sino también en relación con situaciones de terceros particulares." (CNDH, 2020, p. 6) De esta manera señalaba que el Estado tiene la obligación de garantizar el respeto y ejercicio de los derechos humanos aún en condiciones especiales o en razón de las necesidades especiales de cada sujeto.

En este sentido, resaltaba que las personas privadas de su libertad requerían de una protección especial por parte del Estado, dadas las restricciones de movilidad que les habían sido impuestas y la custodia que ejercían las autoridades durante ese periodo señalando, además, que estas personas deben gozar de condiciones de vida dignas que les aseguren el respeto a derechos fundamentales como la vida, la alimentación y la salud. Añadía que, "partiendo del hecho de que la protección a la salud es un derecho humano vital e indispensable para el ejercicio de otros derechos" (CNDH, 2020, p. 9), era imperativo que los Estados redoblaran esfuerzos en tratándose de espacios de internamiento pues en condiciones de encierro la salud puede verse gravemente comprometida.

La idea principal de este pronunciamiento, al igual que la de los realizados internacionalmente, fue requerir una mayor coordinación entre las autoridades responsables de los espacios de internamiento a fin de garantizar el derecho a la salud de las personas detenidas o privadas de su libertad, a través de la adopción de medidas inmediatas y efectivas que evitaran la propagación del virus, tales como el saneamiento constante de los espacios, el suministro de insumos de higiene y el acceso a servicios de salud de calidad, extensivo no solamente para las personas en prisión sino, incluso, para las hijas e hijos que vivían la reclusión junto con sus madres.

Requería además la realización de actividades informativas que permitieran a todas las personas conocer el virus, sus síntomas y medidas de prevención, tomando en consideración los ajustes necesarios para que dicha información llegará, además, a grupos de personas con discapacidad, extranjeras o indígenas. Otra parte importante del documento es la recomendación de adoptar un programa nacional de despresurización penitenciaria en el que se pudieran detectar de mera oportuna casos de SARS-COV-2, para su aislamiento y debida atención, así como efectuar una reclasificación de las personas en internamiento a fin de garantizar su salud e integridad personal.

Nuevamente despiertan interés las medidas sugeridas en el contexto de la pandemia por coronavirus ya que, en el caso del aislamiento, las autoridades estarían obligadas a generar 
los mecanismos necesarios para garantizar que dicha medida atienda única y exclusivamente a las finalidades propias de la pandemia. En este sentido es menester generar mecanismos como protocolos de actuación que aseguren el respeto a los derechos humanos de las personas aisladas. La supervisión constante de la integridad personal es fundamental para respetar no sólo el derecho a la salud, sino la seguridad de las personas detenidas o en internamiento.

No obstante los protocolos de salud en las áreas de internamiento y Centros penitenciarios no deben ser temporales o atender a un fin específico como lo es el coronavirus. Procuradurías, Fiscalías e instituciones penitenciarias, deben adoptar como instrumento permanente de garantía de los derechos humanos, ese tipo de materiales con el fin de asegurar condiciones dignas para las personas, autoridades y demás figuras que transiten por esos espacios. En su caso, los Reglamentos de los distintos espacios deben ser actualizados para incorporar disposiciones atinentes a la salud y definir la responsabilidad de las autoridades en caso de omisión o incumplimiento de sus obligaciones al respecto.

De igual forma que lo hicieren los organismos internacionales, la $\mathrm{CNDH}$ solicitó la priorización de medidas de libertad para evitar la aglomeración de las cárceles o espacios de internamiento requiriendo al poder judicial valorar los casos de personas con riesgos de salud, embarazadas o edad avanzada, que pudieran ser puestos en libertad o accedieran a alguno de los beneficios que marca la ley, sin perder de vista la opinión de las autoridades encargadas de la investigación y persecución de los delitos "a fin de ponderar ante el contexto actual, el derecho a la vida, conforme a un enfoque especial y diferenciado, a los principios de igualdad y no discriminación y al interés superior de la niñez, sobre cualquier otro bien jurídico tutelado" (CNDH, 2020, p. 43)

Para tales fines resulta importante que los Estados sigan las recomendaciones emitidas por el Subcomité de Prevención de la Tortura. Este órgano internacional, derivado de la Convención contra la Tortura y otros Tratos o Penas Crueles, Inhumanos o Degradantes emitió, el 25 de marzo de 2020, diversas recomendaciones tendientes a salvaguardar el derecho a la salud de las personas detenidas, tomando en consideración el impacto de la pandemia y la condición de vulnerabilidad en la que se encuentran las personas privadas de su libertad, con la finalidad de evitar que el contexto fuese utilizado para la realización de prácticas que atenten contra la integridad física de las personas. 
A través del documento intitulado "Recomendaciones del Subcomité de Prevención de la Tortura a los Estados Partes y Mecanismos Nacionales de Prevención relacionados con la pandemia de Coronavirus" (2020), el Subcomité instó a los Estados, entre otras medidas, a realizar evaluaciones de riesgo urgentes para identificar grupos vulnerables ante el COVID19; reducir la ocupación de los centros de internamiento tomando en cuenta las directrices de las Reglas Mandela o las Reglas de Tokio; asegurar la existencia de mecanismos de exigibilidad de derechos humanos; así como promover el uso de las tecnologías en las comunicaciones de las personas en reclusión con sus familiares.

Todo ello con el fin de "reducir la posibilidad de que los detenidos sufran formas de trato inhumano y degradante como resultado de las previsiones reales que enfrentan los sistemas de detención y los responsables de ellos" (Subcomité de Prevención de la Tortura y otros tratos o penas crueles, inhumanos o degradantes, 2020, Pt. I), pues reconoce que las personas en detención o privadas de la libertad pueden sufrir mayores lesiones en sus derechos y que, contextos como el suscitado por la pandemia, puede agudizar dicha problemática. En razón de lo anterior alentó a los Estados a actuar con plena responsabilidad en la atención de la salud de las personas a su disposición, adaptando sus actuaciones a los requerimientos propios de una crisis de salud mundial como la que se vive actualmente.

De todo lo anterior se concluye que el derecho a la salud guarda per se una complejidad y amplitud que requiere de un verdadero compromiso por parte de las autoridades; no obstante, en tiempos de pandemia como la que actualmente se ha vivido los retos propios de la garantía de este derecho se robustecen exigiendo respuestas más rápidas y certeras por parte de las autoridades. Cierto es que las personas en prisión gozan de una condición especial frente al Estado, al encontrarse bajo su resguardo, sin embargo, el desafío que enfrentan los gobiernos hoy es generar políticas de salud adecuadas para garantizar los derechos de este grupo en condición de vulnerabilidad, sin comprometer los fines del sistema penitenciario.

La pandemia por SARS-COV-2 ha dejado múltiples lecciones, sin embargo, posiblemente la más importante de ellas es que la salud es el elemento clave para garantizar una apropiada calidad de vida a las personas, particularmente a quienes se encuentran restringidos en su libertad por lo que, a partir de ahora, los Estados no deberán perder de vista de sus programas de gobierno el fortalecimiento a los servicios de salud en las cárceles o espacios de internamiento, a fin de asegurar en todo lugar y a todas las personas su derecho a la salud, 
fortaleciendo con ello el respeto a su dignidad y el goce efectivo de sus derechos, con independencia de si se vive o no una pandemia.

\section{REFERENCIAS BIBLIOGRAFICAS}

Adhanom Ghebreyesus, Tedros (2017), La salud es un derecho humano fundamental, OMS, https://www.who.int/mediacentre/news/statements/fundamental-human-right/es/

Adhanom Ghebreyesus, Tedros (2020), Alocución de apertura del Director General de la OMS en la rueda de prensa sobre la COVID-19 celebrada el 11 de marzo de 2020, OMS, https://www.who.int/es/director-general/speeches/detail/who-director-general-sopening-remarks-at-the-media-briefing-on-covid-19---11-march-2020

Camacho Solís, Julio Ismael (2014), “La protección del derecho humano a la salud como protección social en el ámbito de los derechos sociales", Derechos humanos en el trabajo y la seguridad social, UNAM, pp. 27- 66. http://ru.juridicas.unam.mx/xmlui/handle/123456789/12580

Caso del Penal Miguel Castro Castro Vs. Perú. (2006, 25 de noviembre), Corte Interamericana de Derechos Humanos.

Caso Tibi vs. Ecuador. (2004, 07 de septiembre) Corte Interamericana de Derechos Humanos.

Comisión Interamericana de Derechos Humanos (1999), Tercer Informe sobre la Situación de los Derechos Humanos en Colombia. http://cidh.org/countryrep/Colom99sp/indice.htm

Comisión Interamericana de Derechos Humanos (2011), Informe sobre los derechos humanos de las personas privadas de libertad en las Américas. https://www.oas.org/es/cidh/ppl/docs/pdf/ppl2011esp.pdf

Comisión Interamericana de Derechos Humanos (2013), Informe de la Comisión Interamericana de Derechos Humanos sobre la situación de las personas privadas de libertad en Honduras. https://dds.cepal.org/redesoc/publicacion?id=2991

Comisión Nacional de los Derechos Humanos (2020), Diagnóstico Nacional de Supervisión Penitenciaria. https://www.cndh.org.mx/web/diagnostico-nacional-de-supervisionpenitenciaria

Comisión Nacional de los Derechos Humanos (2020), Pronunciamiento para la adopción de medidas emergentes complementarias en favor de las personas privadas de la libertad en la República mexicana, frente a la pandemia por COVID-19. 
https://www.cndh.org.mx/documento/pronunciamiento-para-la-adopcion-de-medidasemergentes-complementarias-en-favor-de-las

Comisión Nacional de los Derechos Humanos (2021), Sistema Nacional de Alerta de Violación a los Derechos Humanos, CNDH. https://appweb2.cndh.org.mx/SNA/

Comité de Derechos Económicos, Sociales y Culturales (1998), Observación General No. 9: La aplicación interna del Pacto, ONU.

Comité de Derechos, Económicos, Sociales y Culturales (2018), Observaciones finales sobre a (sic) los informes periódicos quinto y sexto combinados de México. https://hchr.org.mx/comite/comite-de-derechos-economicos-sociales-y-culturales-dela-onu-observaciones-finales-a-los-informes-periodicos-quinto-y-sexto-combinadosde-mexico/

Constitución de la Organización Mundial de la Salud (1946, 22 de julio), Asamblea Mundial de la Salud, https://www.who.int/governance/eb/who_constitution_sp.pdf

Constitución Política de los Estados Unidos Mexicanos (1917, 5 de febrero), Cámara de Diputados. http://www.diputados.gob.mx/LeyesBiblio/ref/cpeum.htm

Corte Interamericana de Derechos Humanos (2020), "Personas privadas de libertad", Cuadernillo de jurisprudencia de la Corte Interamericana de Derechos Humanos.

DE LA TORRE TORRES, Rosa María (2006). El derecho a la salud. En Cienfuegos Salgado, David y Macías Vázquez, María Carmen (coords.). Estudios en homenaje a Marcia Muñoz de Alba Medrano. Protección de la persona y derechos fundamentales, UNAM, p. 301- 315. http://ru.juridicas.unam.mx/xmlui/handle/123456789/11167

Declaración de Alma-Ata, 12 de septiembre, 1978, https://www.paho.org/hq/dmdocuments/2012/Alma-Ata-1978Declaracion.pdf

Declaración Universal de Derechos Humanos, 10 de diciembre, 1948, https://www.un.org/es/documents/udhr/UDHR_booklet_SP_web.pdf

Diario Oficial De La Federación (1948), Convenio para la Promulgación de la Constitución de la Organización Mundial de la Salud, así como el arreglo concerniente a la Office International Hygiene $d^{\prime} \quad$ Publique, SEGOB. http://www.dof.gob.mx/index.php?year=1948\&month=7\&day=10

Díaz Ricardo, Tatiana (2010), “Aspectos internacionales del derecho a la salud”, Saber, ciencia y libertad, Colombia, vol. 5, núm. 1, julio-diciembre, 2010, p. 51-60. https://revistas.unilibre.edu.co/index.php/saber/issue/view/135 
Flores Salgado, Lucerito Ludmila (2015), Temas actuales de los derechos humanos de última generación, Puebla, BUAP-Facultad de Derecho y Ciencias Sociales-Piso 15 Editores.

Gobierno de México, Covid-19 México, 2021. https://coronavirus.gob.mx/

González Piña, Alejandro (2017), "Los derechos sociales y su exigibilidad. Algunos problemas para su protección a través del juicio de amparo", Revista del Centro de Estudios Constitucionales, México, año III, núm. 5, julio-diciembre, pp. 455-491. https://www.sitios.scjn.gob.mx/cec/revista-digital/julio-diciembre-2017

Gros Espiell, Héctor (1985), Anuario Jurídico. Memoria del seminario sobre protección internacional de los derechos económicos, sociales y culturales, UNAM.

Instituto Nacional de Estadística y Geografía (2020), Censo Nacional de Gobierno, Seguridad Pública y Sistema Penitenciario Estatales 2020, INEGI.

Instituto Nacional de Estadística y Geografía (2021), Censo Nacional de Sistema Penitenciario Federal y Estatales 2021, INEGI.

Ley General de Salud (1984, 07 de febrero) Cámara de Diputados. http://www.diputados.gob.mx/LeyesBiblio/ref/lgs.htm

Moreno-Bonett, Margarita y Álvarez De Lara, Rosa María (coords., 2012), El Estado laico $y$ los derechos humanos en México:1810-2010, UNAM, Tomo I. http://ru.juridicas.unam.mx/xmlui/handle/123456789/12006

Noriega CANTú, Alfonso (2016), La creación de los Derechos Sociales en la Constitución mexicana de 1917. En Flores, Imer B. (ed. y comp.) Doctrina constitucional mexicana, $\begin{array}{lllll}\text { Senado de la } & \text { República-UNAM, } & 153-\end{array}$ https://archivos.juridicas.unam.mx/www/bjv/libros/9/4423/15.pdf

Organización Mundial de la Salud (2020), Declaración conjunta de la UNODC, la OMS, el ONUSIDA y la ACNUDH sobre la COVID-19 en prisiones y otros centros de detención, OMS.

Organización Mundial de la Salud (2020), Geo- Hub COVID-19-Sistema de Información para la Región de las Américas, OMS.

Parra Vera, Óscar (2009), "Notas sobre acceso a la justicia y derechos sociales en el Sistema Interamericano de Derechos Humanos", Revista IIDH, no. 50, julio-diciembre, pp. 131157. https://www.corteidh.or.cr/tablas/r25531.pdf 
PINTÓ, Mónica (2012), “Cumplimiento y exigibilidad de los derechos económicos, sociales y culturales en el marco del Sistema Interamericano. Avances y desafíos actuales", $\begin{array}{llllll}\text { Revista } & I I D H, & \text { no. } & 56, & \text { julio-diciembre, }\end{array}$ https://www.corteidh.or.cr/tablas/r30351.pdf

Registro Nacional de Detenciones http://www.diputados.gob.mx/LeyesBiblio/ref/lgs.htm

Subcomité de Prevención de la Tortura y otros tratos o penas crueles, inhumanos o degradantes (2020), Recomendaciones del Subcomité de Prevención de la Tortura a los Estados Partes y Mecanismos Nacionales de Prevención relacionados con la pandemia de Coronavirus, ACNUDH.

Tello Moreno, Luisa Fernanda (2011), Panorama General de los DESCA en el Derecho Internacional de los Derechos Humanos, CNDH.

Tesis 1a. CXXII/2017 (10a.), Gaceta del Semanario Judicial de la Federación, Décima época, Tomo I, septiembre de 2017, p. 218.

Tesis 1a. XXIII/2013 (10a.), Semanario Judicial de la Federación y su Gaceta, Décima época, Tomo 1, enero de 2013, p. 626.

Tesis1a. CXXIV/2017 (10a.), Gaceta del Semanario Judicial de la Federación, Décima época, Tomo I, septiembre de 2017, p. 217.

Tesis1a. CXXVII/2017 (10a.), Gaceta del Semanario Judicial de la Federación, Décima época, Tomo I, septiembre de 2017, p. 219.

Tesis1a./J. 8/2019 (10a.), Gaceta del Semanario Judicial de la Federación, Décima época, Tomo I, febrero de 2019, p. 486.

Tesis 2a. XCIII/2016 (10a.), Gaceta del Semanario Judicial de la Federación, Décima época, Tomo I, septiembre de 2016, p. 841.

Vasak, Karel (1984), Las dimensiones internacionales de los derechos humanos, SERBALUNESCO.

Ventura Robles, Manuel E. (2004), “Jurisprudencia de la Corte Interamericana de Derechos Humanos en materia de derechos económicos, sociales y culturales", Revista IIDH, $\begin{array}{llllll}\text { Costa } & \text { Rica, } & \text { no. } & \text { 40, julio-diciembre, }\end{array}$ https://www.corteidh.or.cr/tablas/r08064-3.pdf

Villanueva Ruth (comp., 2017), Reglas Mínimas de las Naciones Unidas para el Tratamiento de los Reclusos, CNDH. 